\title{
Malignant Bronchial Neoplasm
}

National Cancer Institute

\section{Source}

National Cancer Institute. Malignant Bronchial Neoplasm. NCI Thesaurus. Code C156885.

A malignant neoplasm that affects the bronchial tree. 